Koletzko B. ESPGHAN Distinguished Service Award 2016 to Professor Deirdre Kelly. J Pediatr Gastroenterol Nutr. 2017 Feb;64(2):169-170. doi:10.1097/MPG.0000000000001464.

\title{
ESPGHAN Distinguished Service Award 2016 to Professor Deirdre Kelly
}

Berthold Koletzko, Ludwig-Maximilians-University of Munich, Dr. von Hauner Children's Hospital, München, Germany

\section{Correspondence:}

Berthold Koletzko, Univ.-Prof. Dr. Dr. h.c., Ludwig-Maximilians-Universität München, Dr. von Hauner Children's Hospital, Lindwurmstr. 4, D-80337 München, Germany. Phone: +49 8944005 2826, Fax: +49 8944005 7742, Email: office.koletzko@med.Imu.de

The European Society for Paediatric Gastroenterology, Hepatology and Nutrition (ESPGHAN) presents its Distinguished Service Award - the society's highest award - to an individual who has made a major contribution to the development of paediatric gastroenterology, hepatology or nutrition. The criteria for selection include:

1. Outstanding scientific achievements related to paediatric gastroenterology and/or hepatology, and/or nutrition, usually documented by the candidate's publication and citation record

2. Outstanding contributions to the standards, practice and training in the fields of paediatric gastroenterology and/or hepatology and/or nutrition

3. Outstanding contributions to ESPGHAN as a society

4. Personal integrity

The Selection Committee unanimously agreed to present the 2015 award to Deirdre Kelly, 
Professor of Paediatric Hepatology at the University of Birmingham, Consultant Paediatric Hepatologist and Founding Director of the Liver Unit for Birmingham Children's Hospital NHS Foundation Trust (Figure 1), who scored highest ratings in all these four categories.

Deirdre was born in Calcutta, India and educated in Ireland, where she graduated from Trinity College, Dublin. She trained both in adult gastroenterology and hepatology and in paediatric hepatology in Ireland, the United Kingdom, and the USA. She set up the Liver Unit at Birmingham Children's Hospital in 1989 and developed it into an international unit, demonstrating her outstanding abilities as an innovator, leader and dedicated clinician. Until 2008, the Unit was the only national unit to be designated for small bowel and liver transplantation in the UK. Deirdre and her multi-disciplinary team have transformed survival rates from 40 percent of children surviving liver transplants for one year in 1989 to now 90 percent. Her research interests include molecular genetics of inherited liver disease, the development of stem cell therapy, treatment of viral hepatitis, immunosuppression, and quality of life post-transplantation. She and her team contributed greatly to identify new mechanisms of disease, streamlining diagnosis and establishing new ways of treating children with liver disease. Deirdre is author of several textbooks on paediatric liver disease and has published many original articles and chapters on liver disease, liver transplantation and viral hepatitis.

Deirdre has been Chair or President of numerous national and international professional bodies and has developed a worldwide network, providing training for doctors and nurses to exchange knowledge, both in research and advance is practice, helping to improve treatment and survival rates for a whole generation of children. She was Medical Director of the Birmingham Children's Hospital from 2000 to 2007. She has been President of the British Society for Paediatric Gastroenterology, Hepatology and Nutrition (BSPGHAN) from 2004 to 2007, and of the International Paediatric Transplant Association (IPTA) from 2002 to 2005 She served as Commissioner on the United Kingdom Care Quality Commission (2008-2013) and Healthcare Commission (2007- 2009). Since 2013 she serves on the Council of the United Kingdom's General Medical Council and since 2015 as Non-Executive Director of the Health Research Authority. Recently, Deirde was awarded the great honour of a Commander of the British Empire by her Majesty the Queen Elizabeth II.

Deirde is a very loyal member of ESPGHAN and has contributed greatly to our society, She organized an outstanding hepatology summer school in 1995. She initiated and developed the ESPGHAN Young Investigator Forum that aims to support young researchers and 
served many years on it's faculty, and she was key to shaping this annual event and bringing to the great success that it enjoys until today. From 2001 to 2004 she chaired the ESPGHAN Committee on Hepatology, and from 2006 to 2010 she was President of our society from. Our society owes a great deal to Deirde, to her strategic vision, passion and dedication to introduce and achieve strategically important changes. She reshaped ESPGHAN into a professionally managed association, introduced the annual strategy day, and she laid the fertile ground for many elements that contribute to the success that ESPGHAN enjoys today.

Deirdre is extremely dynamic with enormous energy and strong will, and she is never afraid to stand up for her opinion. She continues to very actively support ESPGHAN, for example by actively contributing to building the ESPGHAN mentorship program for Trainee Members. And she has a great deal of humor, which one can easily recognize by her choice to call the Working Group on Graft Injury after liver transplantation that she chairs the "Gigolo Working Group". Along with Deirdre, also her husband Sir lan Byatt has become a dear member of the ESPGHAN family who is well known as a most stimulating and highly sought after discussion partner in any conversation. When accepting the award, Deidre expressed her sincere thanks to him, her whole family, the outstanding dedicated work of all her colleagues in Birmingham in achieving the high standards of care for our patients and all the colleagues and staff at ESPGHAN for their contributions.

On behalf of ESPGHAN, I wish to congratulate Deirdre and to express our sincere gratitude to her for her outstanding contributions to our field, to promoting child health, and to ESPGHAN. 
Figure 1: Professor Deirdre Kelly

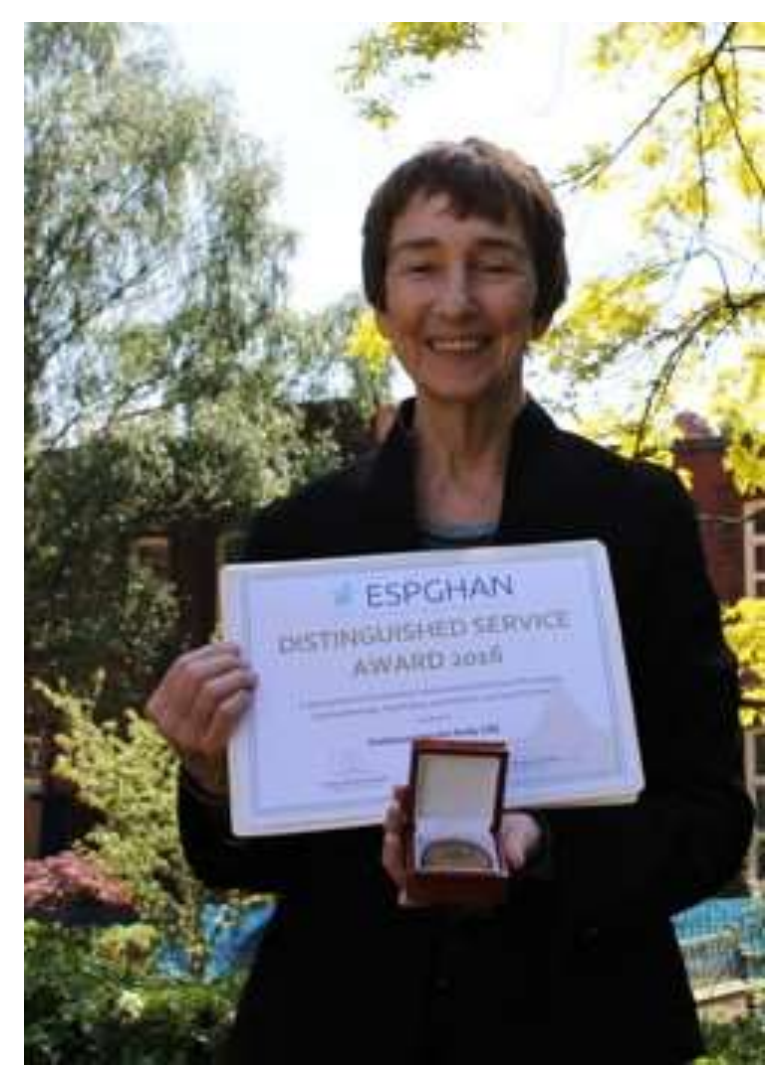

